\title{
INQUÉRITO SOBRE PRESENCCA DE HBSAg EM HABITANTES DE LÁBREA-AMAZONAS
}

Utilizando o método imunoenzimático (ELISA), pesquisamos o HBsAg no soro de 115 pessoas, sendo 8 com hepatite aguda e 107 sem evidência clínica de hepatite. Entre os pacientes a positividade do $\mathrm{HBsAg}$ foi de $50 \%$ (Tabela 1 ) e naqueles não ictéricos encontramos $10,2 \%$ de positividade ( $\mathrm{Ta}$ bela 2). As pessoas incluídas no estudo são residentes no bairro da Fonte, municipio de Lábrea. Nas pessoas sem evidência clínica de hepatite, a positividade do HBsAg foi maior nos jovens, com $8(72,7 \%)$ de positividade na faixa de $0-19$ anos, correspondendo ao que ocorre nas regiões com elevada prevalência do HBsAg 5 .

Tabela 1 - Distribuição por faixa etária dos pacientes com hepatite e resultado do $\mathrm{AgHbs}$

\begin{tabular}{cccc}
\hline Faixa Etária & $N^{o}$ & $\%$ & AgHbs \\
\hline $0-4$ & 1 & 12,5 & POS. \\
$5-9$ & 1 & 12,5 & NEG. \\
$10-14$ & 2 & 25,0 & POS. \\
$15-19$ & 1 & 12,5 & NEG. \\
$20-24$ & 2 & 25,0 & POS. \\
$25-29$ & - & - & - \\
$30-36$ & 1 & 12,5 & POS. \\
\hline Total & 8 & - & 4 \\
\hline
\end{tabular}

A prevalência do HBsAg em individuos aparentemente sadios varia de $0,1 \%$ em alguns paises desenvolvidos da Europa, Estados Unidos da América do Norte e Austrália, a $15 \%$ em vários paises tropicais $^{5}$. Na região de Lábrea tem sido descrito um quadro de hepatite aguda fulminante, conhecida como Febre Negra de Lábrea ${ }^{6}$. Nesta região; através do método de imunodifusão em ágar-gel, dois inquéritos foram realizados, encontrando-se como positividade para o HBsAg 5,1 e 6,5\%, respectivamente ${ }^{16}$. Na região do Rio Solimões, através do ELISA, taxas de 10,2 e $11,4 \%$ de portadores do vírus $B$ foram descritas $^{3} 4$.

Embora a hepatite seja uma doença de ocorrência universal, nas regiōes tropicais, e principalmente no Amazonas, o seu estudo tem particular

Recebido para publicação em 10/7/85.
Tabela 2 - Distribuição das pessoas sem evidência clinica de hepatite segundo faixa etária e resultado do AgHbs

\begin{tabular}{crrrr}
\hline & & & \multicolumn{2}{c}{ AgHbs } \\
\cline { 4 - 5 } Faixa Etária & No & $\%$ & \multirow{2}{*}{. } & $\%$ \\
\hline $0-4$ & 8 & 7,4 & 2 & 18,1 \\
$5-9$ & 29 & 27,1 & 2 & 18,1 \\
$10-14$ & 21 & 19,6 & 3 & 27,2 \\
$15-19$ & 10 & 9,3 & 1 & 9,0 \\
$20-24$ & 6 & 5,6 & - & - \\
$25-29$ & 6 & 5,6 & - & - \\
$30-34$ & 4 & 3,7 & - & - \\
$>35$ & 24 & 21,4 & 3 & 27,2 \\
\hline Total & 107 & - & 11 & - \\
\hline
\end{tabular}

interesse. Primeiro, pela ocorrência da hepatite de Lábrea, cuja etiologia atualmente vem sendo relacionada com o virus da hepatite $\mathrm{B}^{2}$. Segundo, pelo elevado indice de cirrose hepática pós-necrótica, que nos últimos três anos se constitui na primeira causa de óbito entre os pacientes do Instituto de Medicina Tropical de Manaus, e desde sua instalação faz parte das primeiras causas de internação. A utilização de métodos mais sensiveis parece ser importante na realização dos inquéritos epidemiológicos sobre hepatite B. Isto fica evidente quando comparamos os resultados obtidos através do ELISA com os resultados pela imunodifusão em ágar-gel ${ }^{1} 6$.

\section{REFERÊNCIAS BIBLIOGRÁFICAS}

1. Bensabath GJ. Presença do antigeno Austrália ( $\mathrm{Au}$ ) em população do interior do Estado do Amazonas-Brasil. Revista do Instituto de Medicina Tropical de São Paulo 15: 284-288, 1973.

2. Fonseca JCF, Ferreira LCL, Guerra ALPS, Passos LM, Simonetti JP. Hepatite fulminante e febre negra de Lábrea: estudo de 5 casos procedentes de Codajás, Amazonas, Brasil. Revista da Sociedade Brasileira de Medicina Tropical 16: 144-147, 1983.

3. Fonseca JCF, Tavares AM, Simonetti SR, Figlioulo CF, Schtzmayr HG, Simonetti JP. Hepatite em área rural de Codajás (Vila-Cuianã) AM. Aspecto epidemiológico, clínico e sorológico. In: Resumos do XX Congresso da Sociedade Brasileira de Medicina Tropical Salvador - BA, p. 112, 1984. 
4. Fonseca JCF, Tavares AM, Simonetti SR, FerreiraFilho S, Schtzmayr HG, Simonetti JP. Hepatite em área rural de Codajás (Paraná do Oncinha - AM). In: Resumos do XX Congresso da Sociedade Brasileira de Medicina Tropical - Salvador - BA, p.111, 1984.
5. OMS. Progressos en el estudio de la hepatitis virica. Série de Informes Técnicos no 602, 1977.

6. Santos JB. Febre negra na região de Lábrea-Amazonas. Estudo clínico, epidemiológico e histopatológico. Tese de Mestrado. Universidade de Brasilia, DF, 1978.

W. D. Alecrim

L. S. Marreiros

M. G. C. Alecrim

I. K. F. Miranda Santos

Instituto de Medicina Tropical de Manaus,

Universidade do Amazonas 